\title{
Making Open Data Work for Civic Advocacy
}

\author{
AARE PUUSSAAR, Open Lab, Newcastle University, UK \\ IAN G JOHNSON, Open Lab, Newcastle University, UK \\ KYLE MONTAGUE, Open Lab, Newcastle University, UK \\ PHILIP JAMES, School of Engineering, Newcastle University, UK \\ PETER WRIGHT, Open Lab, Newcastle University, UK
}

\begin{abstract}
The value of data in supporting citizen participation in processes of place-making and community building is widely recognised. While the open data movement now permits citizens to acquire governmental data relating to their communities, little to no effort is made to ensure that these datasets are accessible and interpretable by non-professionals. Through a series of community engagements spanning an 18-month period, we codesigned Data:In Place, an open source web tool which supports citizens in accessing, interpreting and making sense of open data. Leveraging visual map-based querying, citizens can access official statistics about their community, interrogate the data, and map their own data sources to create data visualisations. Reflecting on the participatory design process and the designed technology, we provide a framing to make open data work for civic advocacy.
\end{abstract}

CCS Concepts: • Human-centered computing $\rightarrow$ Geographic visualization; Information visualization; Visualization systems and tools; Graphical user interfaces; Visualization toolkits;

Keywords: Open data; data visualisation; data-in-place; sensemaking; civic technology

ACM Reference Format:

Aare Puussaar, Ian G Johnson, Kyle Montague, Philip James, and Peter Wright. 2018. Making Open Data Work for Civic Advocacy. In Proceedings of the ACM on Human-Computer Interaction, Vol. 2, CSCW, Article 143 (November 2018). ACM, New York, NY. 20 pages. https://doi.org/10.1145/3274412

\section{INTRODUCTION}

From life-logging to smart city management, data is at the centre of our worlds, communities, and research. It is estimated that we create 2.5 quintillion bytes of data daily ${ }^{1}$, which means that 90 percent of the data in the world today has been generated in the last two years alone, and with emergent ubiquitous technologies, the data growth rate will likely accelerate even more. With any interaction, whether between environments and people; or people and people - both physical and digital - data is always being generated. But while the technology to generate and store such vast quantities of data is ubiquitous, what remains a significant challenge is how to use that data for the common good.

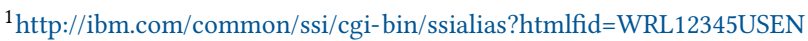

Authors' addresses: Aare Puussaar, Open Lab, Newcastle University, Urban Sciences Building, Newcastle Helix, Newcastle upon Tyne, Tyne and Wear, NE4 5TG, UK, a.puussaar2@newcastle.ac.uk; Ian G Johnson, Open Lab, Newcastle University UK, i.g.johnson1@newcastle.ac.uk; Kyle Montague, Open Lab, Newcastle University, UK, kyle.montague@newcastle.ac.uk Philip James, School of Engineering, Newcastle University, UK, philip.james@newcastle.ac.uk; Peter Wright, Open Lab Newcastle University, UK, p.c.wright@newcastle.ac.uk.
}

This work is licensed under a Creative Commons Attribution International 4.0 License.

(c) 2018 Copyright held by the owner/author(s).

2573-0142/2018/11-ART143

https://doi.org/10.1145/3274412

Proceedings of the ACM on Human-Computer Interaction, Vol. 2, No. CSCW, Article 143. Publication date: November 2018. 
For many years now, private sector industries have been mining big data from different sources in order to understand product demand, forecast business trends, and identify potential business risks. In the public sector too there is a growing emphasis on data-driven, evidence-based policymaking. Different government initiatives are emerging to bring together teams of people to address the challenges of society with data science. For example, institutions like Data Science Campus ${ }^{2}$ in the UK try to find new data sources and ways of providing early statistical indicators, rather than relying on surveys and traditional polling of citizens. The development of the open data movement has begun to overcome the first obstacle to using data for the common good, namely enabling people other than those who generated it to access and use it. But presently, the effective use of big data requires the professional skills of the data scientist. These include skills of being able to access, interpret, and make sense of data in ways that make it valuable, actionable information for others [22] and consequently data science skills are in high demand ${ }^{3}$.

Within $\mathrm{HCI}$ and CSCW research, the rush to big data has surfaced a number of unanswered questions. Where do citizens fit in this data saturated world? Is there a role for them beyond that of simply being the source of data feeding 'Smart' decision algorithms? How do and how could citizens use big data for their own civic and community purposes. Is there a role for 'citizen science' and citizen-generated data in smart city management? How could big data be made accessible and usable by citizens? How could big data be used to inform civic decision-making at the level of local communities and local area planning? And how could all of this be done without the need of a professional data analyst to act as intermediary? Ubiquitous technologies are enabling more $\mathrm{HCI}$ and $\mathrm{CSCW}$ research to be conducted outside the labs with a variety of communities in different contexts [8, 23, 34, 41, 49]. Often, researchers design tools and platforms for data collection, exploration and use, which enable institutions and people to engage with datasets around complex socio-technological issues. There are a variety of data-driven technologies being applied in different civic contexts, from smart cities [32], personal data management [39], community data hubs [14], deliberative democracy [30], and citizen science [5,20]. Many of these systems are designed to elicit participation and collaboration, and provide a common data resource $[1,4]$ for institutions and communities to use and repurpose. However, this can create an unbalanced relationship between professionals using the data to make decisions on behalf of citizens [47], while citizens lack the skills, knowledge and appropriate tools to use the same data in civic advocacy. Furthermore, this gives rise to significant tensions relating to the multiple ways in which these datasets are made legible and interpreted.

In designing platforms to support communities and institutions working together with data, there are significant challenges and questions relating to how data may be relevant and for whom, and how to translate and represent it in ways that make it accessible and effective in supporting civic action. There are also challenges and questions as to how different datasets might be combined to better support the communication, collaborative interpretation and use of complex data sets that straddle boundaries between data that is private, shared, or public. A crucial role for the professional data analyst is to understand complex community contexts so that they can identify useful data and help communities make sense of data in ways that is relevant and actionable within their context. In HCI and CSCW, researchers have stressed the importance of providing additional contexts to support the process of making sense of data $[6,17]$. For example contextualising data in interpersonal 'worlds' by focusing on the nuances and implications of understanding data as bound to places and communities [34,44]. A key challenge in this regard is to find ways to support individuals and communities in finding data that is relevant to the issues and concerns

\footnotetext{
${ }^{2}$ http://datasciencecampus.ons.gov.uk

${ }^{3}$ http://blog.linkedin.com/2017/december/7/the-fastest-growing-jobs-in-the-u-s-based-on-linkedin-data
} 
that are intimately tied to the community's construction of place - the locales, neighbourhoods and regions in which they live and in which their values and futures are invested. The challenge then is understanding what is involved in supporting citizens in making data relevant to place to enable effective action in relation to place-based issues and concerns.

Given this agenda, there is a clear need to work with local communities to co-design more inclusive processes and digital tools that would not only enable the community to access open data but also help to democratise the practice of data science itself. To that, we posit that such practices and digital tools need to be framed by the following principles:

(1) Place can be used as a way to make open data relevant to communities.

(2) Communities need to be able to make sense of and challenge open data in relation to their own experiences and their own data.

(3) Local knowledge can be used to enrich and promote collaborative exploration and evidencing of issues for civic action.

In this paper, we describe the 18-month iterative co-design and development of Data:In Place, an open-source platform to support inclusive processes of accessing and making sense of open data for the purpose of civic advocacy. Throughout this co-design process with local communities and charity organisations we positioned ourselves as data scientists, collaborating in and supporting their community research with our technical expertise. This served as a means to understand what the communities' data needs were and what sort of platform would be of value to them As we uncovered new barriers and challenges to the engagement of non-professionals with data science, we co-designed and developed new features and functionality for the platform to support their access and use of these techniques (see Section 4). We designed the system through in-depth collaboration in two community contexts: (1) a neighbourhood-planning group relying on open data to inform the process of policymaking, (2) charity organisations reliant upon data to focus their work based on the needs of the community, and to illustrate their impact to extend their funding.

\section{OPEN DATA FOR CIVIC ADVOCACY}

\subsection{Finding Open Data}

Increasingly, data is gathered from places and about the people living and working in them. This is done with an aim to inform polices, to help optimise resources and to improve the lives of citizens $[11,31]$. However, when these datasets are made open they can potentially be used for novel forms of participation, democracy, and social interactions [11,28]. Having government and private sector releasing data creates potential opportunities for data-driven civic participation [45]. Making data open not only has the potential to promote transparency and openness, it may also serve to shift the power relationships between ordinary people and decision-makers away from transactional models of information services to more relational ones [36, 40].

With the growing popularity of the open data movement [2], crowd sourced data [33] and commercial companies sharing their datasets ${ }^{4,5,6}$, UK government institutions (and multiple other countries) are also releasing statistics from official sources as open governmental data (OGD) under Open Government Licence ${ }^{7}$ in order to invite communities and a wider field of players to re-use the data and provide solutions and services [29]. An example of this is CivTech ${ }^{8}$, the

\footnotetext{
${ }^{4}$ http://movement.uber.com

${ }^{5}$ http://labs.strava.com

${ }^{6}$ http://developer.zoopla.co.uk

${ }^{7} \mathrm{http}: / /$ nationalarchives.gov.uk/doc/open-government-licence/version/3/

${ }^{8} \mathrm{http}: / /$ civtech.atlassian.net
} 
Scottish Government's initiative to drive public sector innovation with the help of private sector and citizens. There are already multiple systems in place from different central governmental departments to provide the public access to these raw datasets of official statistics ${ }^{9,10,11,12,13,14}$, as well as initiatives from local governments to release locally collected data ${ }^{15,16,17}$. This led to new digital tools (both free and commercial) being created to aid community groups to make use of that data (see Section 2.4). One example is MapIt ${ }^{18}$ - a tool that displays constituency, parish and local council area for an inputted postcode. However, there has been critique that the 'measure of openness' for governmental institutions is how many datasets and repositories they have online [15] and that there are more nuances to the effective re-use of open data than simply the ability to access the raw data files. Making data available is not the same as making it usable for everybody. Furthermore, there is often a distinction between those who collect the data, those who need to use it and for what purpose, and those who can access it. When citizens do not have the skills to access or make sense of data and to use it for effective action, it is difficult to claim it is 'open data' [1]. Many of the existing solutions and tools, despite aiming to make open data more accessible to communities, often link to static datasets, are not freely available or lack the functionality necessary to help citizens understand and find value in the data.

\subsection{Working with Open Data}

In addition to the issues around access and limitations with existing tools, there are a number of other barriers to the 'effective use' [24] of data within communities: resources, digital literacy, competencies, trust and ownership. Gurstein [24] points out that we should not confuse access with use of open data. As described in the previous chapter there has been a lot of effort to make data available for whoever is interested in it, but little has been done towards making data accessible and usable for non-professionals, especially those who are deprived and marginalised. Gurstein is critical of Tim Berners-Lee's take that open data empowers 'everyone', because the fact is that it only empowers the ones that have access to the resources to and knowledge to make use of it. He suggests that we should adopt the concept of 'effective use' to distinguish access from accessibility and use. In this case we should distinguish 'open data' from 'accessible data'. The former refers to the classical definition of open governmental data ${ }^{19}$ whereas the latter is the one that would truly make open data open and accessible, because simply having access to these different raw datasets does not mean better civic engagement and participation from citizens [15] In his article, Gurstein puts forward a seven-layer model to address the 'data divide' [24]. Layers include: (1) internet, (2) computers and software, (3) computer/software skills, (4) content and formatting, (5) interpretation/sensemaking, (6) advocacy, (7) governance. Whilst Gurstein's model adequately captures the challenges of addressing 'data divide', Hakken [25] also argues that these barriers cannot be overcome by technology alone; human actors play a vital role. Information and knowledge does not magically appear from data, it needs to be constructed by humans, not

\footnotetext{
$\overline{{ }^{9} \text { http://data.gov.uk }}$

${ }^{10} \mathrm{http}: / /$ data.police.uk

${ }^{11} \mathrm{http} / / /$ opendatacommunities.org

${ }^{12} \mathrm{http}: / /$ nomisweb.co.uk

${ }^{13} \mathrm{http}: / / g$ geoportal.statistics.gov.uk

${ }^{14} \mathrm{http}: / /$ ukdataservice.ac.uk

${ }^{15}$ http://datamillnorth.org

${ }^{16}$ http://data.london.gov.uk

${ }^{17}$ http://open.manchester.gov.uk

${ }^{18} \mathrm{http}: / /$ mapit.mysociety.org

${ }^{19}$ http://opengovdata.org
} 
computers. Furthermore, expert systems of data and information retrieval do not deal adequately with the social and cultural dynamics at the centre of the knowledge networking [25].

The idea of 'democratising data science' has emerged from research which calls for new tools and approaches that leverage data science for social good $[9,10]$. Choi and Tausczik [9] investigated collaborations around these kinds of open data projects and found that they are small in scale and mainly involving civic hackers and data journalists [38]. These projects aim to address problems for the social good, however it is clear that more could be done to include the community to contribute to this knowledge creation. Although there have been efforts to link together data experts with non-profit organisations to aid them achieving their goals [18], this is likely to produce a reliance on experts to provide constant support. Also, the exclusion of actual problem owners (i.e., the people on the ground) from these processes is worrisome. It can mean that experts and scientists decide of which problems to tackle and how to interpret the data. More should be done by creators of technologies for working with data to reach groups with low or non-existent data science capacity [10].

Taylor et al. [44] posit that data should be understood as intrinsically linked to sense of 'place' arguing that data should be kept in the context it was collected and questioned to produce better understanding and use of it. Nevertheless, with open data, it is already collected and taken away from those places by outside players and the people living there did not have any say about how the data has chosen, collected and interpreted. These datasets often lack a representation of place that is essential to contextualise and situate them with community and the activities they engage in, the concerns and issues they face, and the situations they want to change. Only when these things are better understood can we turn our attention to understanding how people reconstruct new meaning and knowledge from these already engineered datasets. Work in this area has reported on 'sensemaking' with personal informatics [39] and with domestic data in the workplace [12]. In both studies, people created meaning from the data through 'comparison' and linking it to 'real life experiences'. Despite this work showing promise for better engagement with data and an understanding of what data is and what it means, none of this work has confronted the problems of 'effective use' (e.g., civic action).

\subsection{Integrating Open Data with Citizen-generated Data}

Data about citizens and communities is collected and used by institutions for specific purposes. Releasing such data as open data is a useful by-product of those processes, and one which can potentially make the processes and purposes more transparent. However, for citizens to be able to challenge that data or those processes, they have to be able to talk back to the data either with comments or opinions, or with data of their own. In theory, the availability of open-source software and hardware tools ${ }^{20}$ enables people to take democratic matters into their own hands [1, 3, 4]. However, despite available tools showing promise for better engagement, very few opportunities exist for less privileged communities to collect their own data and have an impact on decisions that affect their lives, and those of their families and neighbours [13]. Moreover, it is often difficult to identify what data is relevant, worth collecting for the community or even possible to quantify. We can apply the idea that, "not everything that can be counted counts, and not everything that counts can be counted" [7] when taking on data-driven decision-making.

There are several opportunities for open data to have an impact on the lives of citizens, and even empower them, but this requires citizens with skills, literacy and tools to access, interpret and contribute their own data to existing datasets. Part of the potential is around establishing a more holistic picture of the community [46]. Making data accessible and relevant for people also has the

$\overline{{ }^{20} \mathrm{http}: / / \text { arduino.cc }}$ 
Table 1. Comparison of Open Data Platforms for local communities and non-professionals

\begin{tabular}{|c|c|c|c|c|c|}
\hline PLATFORM & DATASETS & ACCESS & CONTEXT. & EXPAND. & OPENNESS \\
\hline $\begin{array}{l}\text { UK Census- } \\
\text { data }\end{array}$ & $\begin{array}{l}\text { Static Census } \\
2011\end{array}$ & $\begin{array}{l}\text { Search } \\
\text { datasets by } \\
\text { postcode or } \\
\text { drill down } \\
\text { from country } \\
\text { level }\end{array}$ & $\begin{array}{l}\text { Displays official } \\
\text { boundaries on the } \\
\text { map and a fix } \\
\text { set of charts and } \\
\text { graphs }\end{array}$ & Not possible & $\begin{array}{l}\text { Free to use, } \\
\text { proprietary }\end{array}$ \\
\hline $\begin{array}{l}\text { Know My } \\
\text { Neighbour- } \\
\text { hood }\end{array}$ & $\begin{array}{l}\text { Fixed set of } \\
\text { different so- } \\
\text { cioeconomic } \\
\text { dataset }\end{array}$ & $\begin{array}{l}\text { Web and PDF } \\
\text { reports based } \\
\text { on requested } \\
\text { area (e.g., } \\
\text { user provided } \\
\text { boundary) }\end{array}$ & $\begin{array}{l}\text { Displays official } \\
\text { boundaries on a } \\
\text { static map. Fixed } \\
\text { set of charts and } \\
\text { graphs }\end{array}$ & Not possible & $\begin{array}{l}\text { Commercial, } \\
\text { proprietary }\end{array}$ \\
\hline $\begin{array}{l}\text { Community/ } \\
\text { Local Insight }\end{array}$ & $\begin{array}{l}896 \text { different } \\
\text { socioeco- } \\
\text { nomic dataset } \\
\text { (up-to date) }\end{array}$ & $\begin{array}{l}\text { Web appli- } \\
\text { cation for } \\
\text { exploring and } \\
\text { PDF reports }\end{array}$ & $\begin{array}{l}\text { Enables drawing } \\
\text { areas on a dy- } \\
\text { namic map. Fixed } \\
\text { set of different vi- } \\
\text { sualisations }\end{array}$ & $\begin{array}{l}\text { Adding own } \\
\text { organisa- } \\
\text { tional data } \\
\text { via file with } \\
\text { postcodes }\end{array}$ & $\begin{array}{l}\text { Commercial, } \\
\text { proprietary }\end{array}$ \\
\hline
\end{tabular}

Source: Table created by the author

potential to transform it into a resource that encourages debate and deliberation and can open up new ways of participating $[5,27]$.

\subsection{Existing Open Data Platforms}

The popularity of open data and the availability of different data sources has stimulated the development of a variety of platforms to make use of these datasets. We will go through some of the most popular free and commercial tools used by communities and non-professionals (based on our engagements with different communities) to make use of open data. We deliberately excluded official platforms like UK Police Crime Map ${ }^{21}$, Public Health England's Fingertips Tool ${ }^{22}$ and open data demonstrators like the Indexes of Multiple Deprivation (IMD) Explorer ${ }^{23}$, because they are meant to help people interact with a specific dataset, illustrating the mean of production of that data. Instead, we focus our discussion on tools intended for exploration of multiple datasets. We broadly assessed the existing open data platforms based on the following criteria (see Table 1): their ease of access to work with the data; the support provided for contextualising the data with communities or issues; the expandability of the available data for working with, and openness of the tools concerning paywalls and collaboration.

The major drawback of the existing platforms is their lack of expandability to support the incorporation of new datasets. The de facto standard is to provide a fixed and curated set of open data, meaning that new data captured within communities would not easily be contextualised with the national statistics and datasets. One platform, Local Insight, that did allow users to upload their own datasets, had specific requirements on the formatting of the data and that data was only

\footnotetext{
$\overline{21} \mathrm{http}: / /$ police.uk

${ }^{22} \mathrm{http}$ ://fingertips.phe.org.uk

${ }^{23}$ http://dclgapps.communities.gov.uk/imd/idmap.html
} 
available to the organisation that uploaded it - making collaboration with others in the community challenging. Moreover, as this platform is intended for commercial use, carrying large subscription fees, it excludes marginalised communities. In addition to limiting the availability of datasets for working with, the existing platforms are restrictive in the forms of access to data interrogation and query manipulation, opting instead to provide sets of predefined PDF reports. Though informative and well presented, the reports are merely a curated representation of the statistics as seen by the organisation that published them, with no support to inspect or contest the contents. For a community to take action on matters that affect them, they need tools that support accessing, interpreting and making sense of open data. While the existing platforms can provide support for these tasks, they fall short of supporting non-professionals through the entire process.

\section{CO-DESIGNING FOR ACCESSIBLE DATA}

According to existing literature and studies, it is evident that there is great potential in using data as a tool for civic advocacy. However, there are still barriers and a lack of available digital tools to access data and make it meaningful and useful for people. Before we can jump into civic advocacy and action, we to need take a couple of steps back and address the issues around access, interpretation and sensemaking. We were interested in investigating these challenges in more depth and sought out people and groups who could benefit from having easier access to data, and the ability to use it in their endeavours. We took up a participatory action design approach [51] to identify the needs and uses for data within communities and built a system that would respond to these needs, taking account of the local practices and cultures. The process of building the system was not a one-off: design $\rightarrow$ develop $\rightarrow$ deploy. The system evolved through an iterative process, with different stakeholders and potential users of the system over a period of one and a half years. We co-designed the system through two-to-three week design cycles, during which, we added features and functionality to the system, based on the input and participation of our co-designers from the community organisations with which we collaborated. We present findings from the research team's field-notes and observations at community meetings, focus groups, interviews and feedback sessions with different stakeholders - two local government workers (LG), six charity workers $(\mathrm{CW})$ and eight community volunteers $(\mathrm{CV})$ from a range of roles. We transcribed and analysed the interviews, focus groups and feedback sessions to guide the ongoing design of the platform.

In the following sections we describe the chronological and in-depth process we went through to inform the final design of Data:In Place, an open-source place-based data exploration system. The online platform brings together data from official governmental sources with data generated by communities and citizens, and links it together around 'place'. The design aims to help nonprofessionals access, interpret and make sense of data for potential uses in local decision-making and civic advocacy.

\subsection{Study Context}

In December 2016, we started working with a group of residents who were interested in starting a Neighbourhood Plan for their local area. A Neighbourhood Plan [16] is one of the processes put in place by the Localism Act (2011) in the UK, which devolves power away from central and local government directly to citizens. The local policy process enables communities to write their own statutory planning policy which will be added as a part of the local planning policy [16, 21, 42]. As part of the local planning process, the group identified the need for data to provide evidence to inform the creation of their local planning policy. During this time, we also started collaborating with a local charity organisation who focus on the health and wellbeing of young people by providing opportunities for physical activity, training, coaching and education. The charity was 
interested in using insights from data to focus their interventions in areas of the city that could be supported by the external funding sources they acquired, as well as providing other evidence of the impact of their interventions, again related to future funding applications and renewals.

\subsection{Accessing Data}

Both groups approached us with a request to support them in accessing open datasets to support their work. The neighbourhood-planning group - which was made up of various people from community voluntary and charity sector organisations and local residents - had collated some data on the defined neighbourhood plan area from the local government website in the form of 'ward profiles' (i.e. political boundary). This was a document with collated statistics from various governmental departments (e.g., age, population, employment) represented in tables and graphs. The charity organisation had their own administrative data, which included some basic demographic information on the clients of their services, and some Census data for the City. Before people could start to think about what kind of data they would need to evidence their issues they needed to get an idea of what was out there already. To get an idea of what sort of data they would need, we started attending community meetings where neighbourhood plan priorities were discussed. During community meetings, residents and people working in the area marked down the priority list of local issues or important areas they wanted to focus on. These were categorised under themes: issues around housing, anti-social behaviour, local environment concerns, open spaces and play areas. The concerns and proposals were local for these people and things that they thought must be prioritised. We then took this list and sought out all the official data published by the government and other institutions that relate to it. For example, anti-social behaviour was evidenced from local police data and for housing we found data about housing ownership from the Office of National Statistics. Although, this data was already in the 'ward profile' it could not be interrogated at the neighbourhood level. These datasets consisted of different types of data - static documents and reports, machine readable files, links to application programming interfaces (APIs) etc. We then presented all these datasets at the next community meeting. Although people were excited by the idea of getting their hands on the data which governmental structures use to make decisions in the area, they found it hard to grasp exactly which areas and what statistics they represent. This meant that people were relying on the research team to access, make sense of and interpret these datasets. Furthermore, people started asking additional questions about the data, which meant that we would have to go back and get all the data sources again with new query parameters. The questions this exercise raised necessitated re-interrogation of the original datasets with new query parameters. This illustrated the issues with static datasets and the difficulties of data access for non-professionals. This led us to build the first functionality of Data:In Place to bring all of this open data from different governmental departments together into one place (see Section 4.2).

\subsection{Adding Relevant Data}

Aggregating all of the datasets requested by the community into a single system that they could access was not enough, as much of the data lacked relevance to their specific local community. The forms that data is captured, stored and presented in by institutional structures does not resonate with people. They do not see places as numerical codes in a dataset; they associate them with what they see when they are going about their everyday lives. When we presented one of the charity workers (CW2) involved in the planning group with the data they had requested, they were concerned with the lack of context:

"Should be street names or post codes for people to understand where the data is coming from." 
To make this data relevant to people we needed to start with things that are familiar to them. Local government worker LG1 points out the different ways neighbourhoods are constructed:

"Everybody defines their neighbourhood slightly differently, from a council perspective, we're often looking at lower super output areas, we know that's not a, we know people don't have defined neighbourhoods necessarily, some people would define their neighbourhood literally as a few houses, others as a few streets, others as more of an estate, um type area. But it's information or stuff that you can kind of drill down to at a very local level, and things which are important to people at a very local level."

Based on these ideas we re-designed the platform to enable the starting point for exploring these datasets to be place. We used geographic reference points to automatically link together datasets for people to start exploring in relation to the places they live and/or work (see Section 4.1). The simple design principle of these features was to improve accessibility of open governmental data for communities and put it into context with the issues that were important and relevant to them. We now had not only brought relevant datasets from different sources together, we also had bounded it into place. We added further available datasets in the system as a direct response to the interest of groups we were working with. However, every time we ran a session with a group, they identified new datasets of interest. There was a plethora of data available that we could add to the platform, but it was not valuable to add all of them. As such, we started by asking people what they did, and did not deem useful in terms of what they could relate to the issues they were trying to evidence or tackle. Again, this resulted in a flurry of requests from our collaborators meaning we were spending a lot of time going back to them with different datasets. We did not want our groups to have to rely on our availability in order to access data, nor did we have the capacity to provide them with data in a timely manner. Instead, we added a 'request data' feature that enabled people to express a desire or add an idea of what kind of data they required (see Section 4.3).

\subsection{Additional Administrative Data}

The functionality of adding new open datasets to the platform quickly prompted groups to request that their own organisational data be added to the system. They were keen to compare their own data and interpretations against the open datasets they had access to through the system. For the charity organisations operating in the area it provided a way to evidence the work. CW3, for example, explained that it would help shape their group's service provision, ensuring they were using their public funding to deliver the services where they were needed most:

"Our own data is really important, but also the publicly available data we are looking at here is really useful for us for shaping where we want to go and where we want to work. So, for example [...] we would like to be able to do is map out where those participants of ANON program are coming from. And map that onto like Indexes of Multiple Deprivation. So, that we can see that we are actually in there ... if we say we are working with the most deprived communities, can we prove it?"

They also discussed how this would help ensure the ongoing funding support for the charity by creating evidence of their intervention work:

"So, it's all sort of very well for the founders, we can say the right things, but for ourselves and our growth and being able to really demonstrate publicly this sort of tool would be really useful for us to be able to say "look these are the areas in the ANON which we cover" and we are covering all these more deprived areas."

For the neighbourhood planning group it enabled them to contest some of the official data by adding some of their own data, which they collected themselves from the community. For example, 
they were interested in seeing how people's opinions about where they lived and their feelings of wellbeing mapped against official statistics for crime and employment. We received multiple requests from people wanting to add their data into the system and often the data was sent to us in different formats. We implemented the ability for people to upload their data to the system, and have it mapped alongside the official data (see Section 4.4). The ability to easily map and compare their own data with official statistics really brought meaning to the official datasets by putting it into the context that people were in.

\subsection{Adding New Data}

By this point in the co-design process, the system had added functionality that enabled access to open datasets, and for people to see these data in the context of their community, and to compare and contrast other open datasets with their own administrative data. Issues started arising around what these datasets represent. People were worried that what they were seeing did not reflect the actual issues and concerns of the neighbourhood. They felt they could not find the answers to the community's questions from the data. As such, there was a need to 'create new data' that was closer to providing a more accurate picture of their experiences of the community. CW4 made us aware of this in terms of the negative and restrictive perception associated with the data:

"[...]"they're at the lowest $10 \%$ of blah dee blah" and this, that and the other and "they're such a deprived community" and I think it might be actually quite nice to present some positive data to them, you know. I don't know if there is any, but maybe there is."

We wanted to incorporate into the platform the ability for residents to capture and upload locally relevant data. $\mathrm{CW} 3$ reflects a resistance against a version of the community that was reduced to numbers:

"I mean I think a lot of people would think of data and think of it purely as numeric but I think of data as being any kind of information that you've gathered to understand a situation."

For this, we envisioned photographs, sensor data from citizen science kits, online comments and viewpoints and voiced concerns of citizens. This posed a challenge of how to get people's voiced concerns into the platform. We started off by recording people's opinions about places and concerns in community workshops specifically designed to capture opinions about place, that we could pin-point to locations as short audio recordings on the map within the system (see Section 4.5).

Throughout the co-design process, we developed our system in response to our collaborators' requests and questions. As each new feature was added, it was interesting to see how our collaborators' relationship with the data changed. They became first more curious about what they could access, then experimental as they asked for an increasing amount of data to compare. Later in the process, they wanted more control and personalisation of data representation, and finally moved toward a level of criticality toward data. In the following section, we outline how this process informed the design of our system.

\section{DATA:IN PLACE PLATFORM}

In the following sections, we will describe the capabilities and features of Data:In Place that we developed as a response to the engagement with the stakeholders in more detail. The Data:In Place platform leverages the capabilities of the visualisation framework RAWGraphs [35], which comprises: (1) load your data, (2) choose a chart, (3) choose your dimensions, (4) customise your visualisation and (5) download. We will discuss in depth the added feature extensions we built to extend the capabilities to make it more usable in the context of open data and civic advocacy, as informed by our design principles and co-design process with the people. Based on the literature 
and the experience of working with the communities and the issues we countered around accessing and making sense of open datasets we ended up implementing the following features: (1) visual map based query system for the datasets, (2) automatic linking to different governmental APIs in one place, (3) ability to add or request interesting datasets to be added to the platform, (4) ability to add own datasets for mapping and comparison with the official sources, (5) merging of qualitative and quantitative data in order to create a link between public opinion data and socio-demographic characteristics from official statistics.

\subsection{Map Based Queries}

A person's first interaction with the system starts with defining a place they are interested in bounding the 'data-in-place' [44]. For this purpose, we implemented a map component to the system where people can explore and find the place they are interested in. It enables people to search for postcodes or just pan around the map to find places of interest (e.g., home, work or potential engagement area). After finding an area of interest it can be selected by drawing a boundary around it on a map. We implemented the map component by using open-source mapping framework Leaflet $^{24}$ and tiling service MapBox ${ }^{25}$, which uses tiles from OpenStreetMap ${ }^{26}$ (Figure 1). Data:In Place uses open standards for further expansion of the mapping capabilities e.g. adding different base maps or extending geographical manipulation tools. After drawing a boundary on a map, the platform automatically retrieves polygons of the intersecting governmental areas ${ }^{27}$.

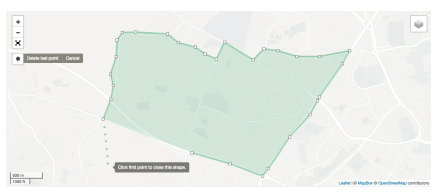

(a) Drawing a boundary to define a query

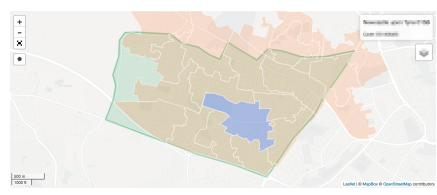

(b) Retrieving intersecting area polygons

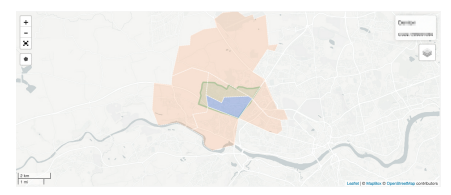

(c) zooming out to retrieve new level area polygons

Fig. 1. Map Based Queries

RAWGraphs [35] was intended to be a front-end-only solution without any server-side logic, however we implemented a server side logic using NodeJS ${ }^{28}$ and PostgreSQL ${ }^{29}$ with PostGIS ${ }^{30}$ to handle geographic queries. By zooming in and out of the map, the system switches between different administrative levels (i.e. output areas, wards, local authorities, counties, regions, countries). The polygons are updated and redrawn on the fly while zooming in and out on the map. Using the map component, people can define their query for open datasets by just exploring the areas and defining places (i.e. drawing boundaries) of interest.

\subsection{Accessing Official Datasets}

The existing functionality of RawGraphs [35] had three ways to "load your data" into the platform: copy and paste plain text from any source, upload a machine-readable file (CSV, TSV, XLSX, JSON) or request data from an API endpoint URL. In addition, it has a section for loading sample datasets

\footnotetext{
${ }^{24}$ http://leafletjs.com

${ }^{25}$ http://mapbox.com

${ }^{26} \mathrm{http}: / /$ openstreetmap.org

${ }^{27} \mathrm{http} / / /$ geoportal.statistics.gov.uk

${ }^{28}$ http://nodejs.org

${ }^{29} \mathrm{http}: / /$ postgresql.org

${ }^{30} \mathrm{http}: / /$ postgis.net
} 
to demonstrate the capabilities of the visualising framework. We replaced the sample datasets sections with a list of official datasets (Figure 2a) that people identified important (see Section 3.2). However, these datasets are not static, they are links to real-time API endpoint URLs which are compiled to retrieved data about the specific place defined with the map-based query (see previous section). This means that the platform is always up-to-date with the latest dataset. Zooming in and out of the map while a dataset is selected automatically redefines the query and retrieves a new set of data (Figure $2 \mathrm{~b}$ ) specific to the place on the map. This makes the retrieval and comparison of statistics easier, but also displays the areas intersecting with the boundary representing contextual information (Figure 2c).

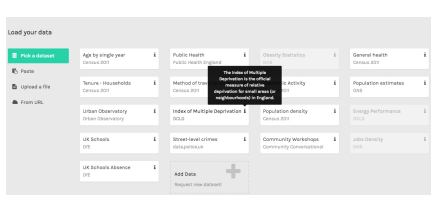

(a) List of open datasets

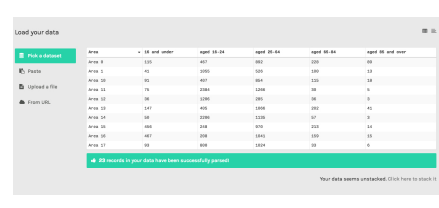

(b) Retrieving data from source

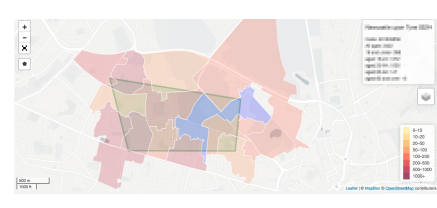

(c) Visualising data with boundary

Fig. 2. Accessing data

\subsection{Adding Official Datasets}

Similar to RAWGraphs' [35] ad-hoc visual models, whereby anyone can add their own visualisation templates to be used by the community, we wanted to enable people to add new official data models to the list. The functionality to add a simple dataset from a file and/or API endpoint URL already existed, however in order to make use of "map-based queries" it needed to include the correct parameters to pass in the URL. We ended up adding a simple form dialog to request data, so people could link to the desired dataset they wanted to include in the system (Figure 3).

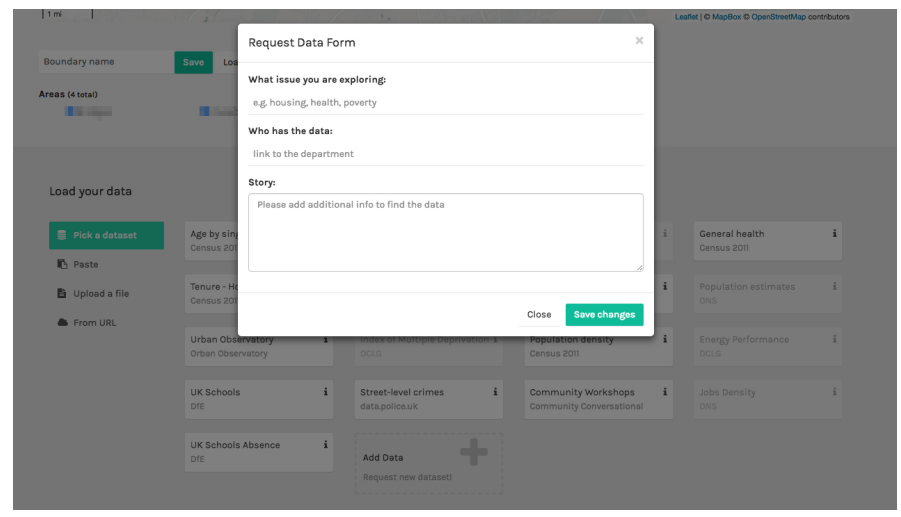

Fig. 3. Screenshot of the Data Request Form

This was then saved to our database and we could make the link between the new source and map query and add it to the platform. This also enabled people to add requests for potential datasets they would like to see on the system without knowing the exact sources. This relates to our first decision of how we, as the researchers, chose which datasets should be in the system - they were related to the issues that people identified as important and wanted to investigate and evidence through the use of data. 


\subsection{Mapping Community Data}

The added mapping component opened up new features for geographic manipulations and data to be mapped alongside official datasets. We extended RAWGraphs' data type parser to identify geographical data (e.g. longitude/latitude data, Geographic JavaScript Object Notation (GeoJSON), postcodes, Office for National Statistics (ONS) $\operatorname{codes}^{31}$ ). Similar functionality can be found in current state of the art online mapping tools, such as Carto ${ }^{32}$. However, our system tries to automatically understand the data by looking at the headers and the content without any human intervention, mapping it on the go (Figure 4b,4c). If the system has not successfully georeferenced the data, it has controls for people to do it manually. The system uses implemented algorithms in regular expression language ${ }^{33}$ to identify and match patterns, and GeoJSON ${ }^{34}$ parser to enable automatic georeferencing (Figure 4a).

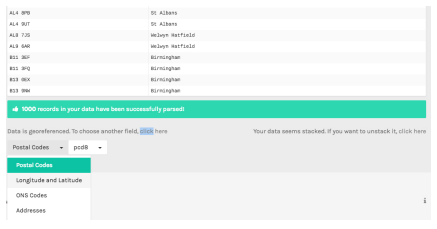

(a) Georeferencing

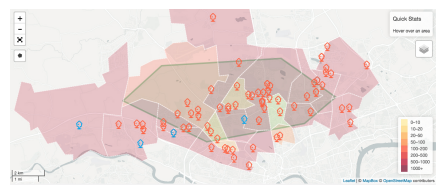

(b) Mapping point data

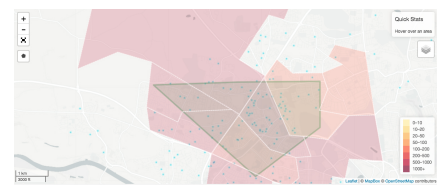

(c) Mapping postcodes

Fig. 4. Mapping Community Data

\subsection{Adding Citizen-Generated Data}

Public opinion data in form of audio recordings from community workshops was added to the platform as another data source. The whole audio was time and geocoded, having a database entry for each coded opinion. This also meant it could be accessed similarly as other datasets using the map based query system and getting all the people's opinions in a specific place. Feeding this data into the system also bounds it within the governmental boundaries, creating a geographic link between public opinion data, and socio-demographic characteristics from official statistics. When choosing an opinion from the list (Figure 5b), the system will automatically add the marker on a map and start playing the place-based recording (Figure 5a). As such, we can integrate the public opinion data into the system side by side with the other datasets. For example, exploring crime statistics while listening to people talk about issues around anti-social behaviour on a particular street or looking at the availability of developing land in an area, while listening people talk about the lack of play areas for children.

\section{DISCUSSION}

Through our exploration of the current state of open data platforms and co-designing the Data:In Place platform with the communities over an 18-month period, we brought to the surface a number of issues around using data in the context of civic advocacy and action. It quickly became evident that communities could see the value of data and its importance in civic action, however the barriers to accessing and understanding its relevance to local matters distanced them from using it effectively. This meant that people were often reliant on third-party professionals to lead in

\footnotetext{
${ }^{31} \mathrm{http} / / /$ wikipedia.org/wiki/ONS_coding_system

${ }^{32}$ http://carto.com

${ }^{33}$ http://wikipedia.org/wiki/Regular_expression

${ }^{34} \mathrm{http}: / /$ geojson.org
} 


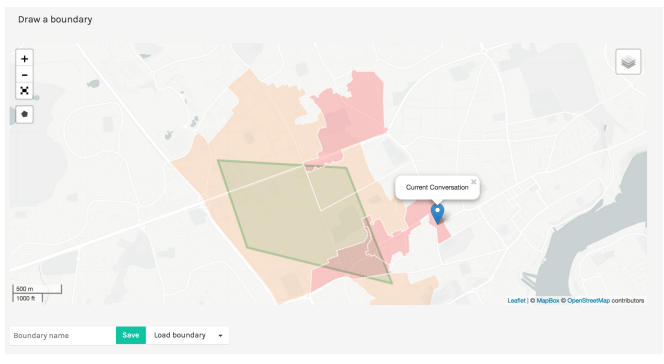

(a) Map query

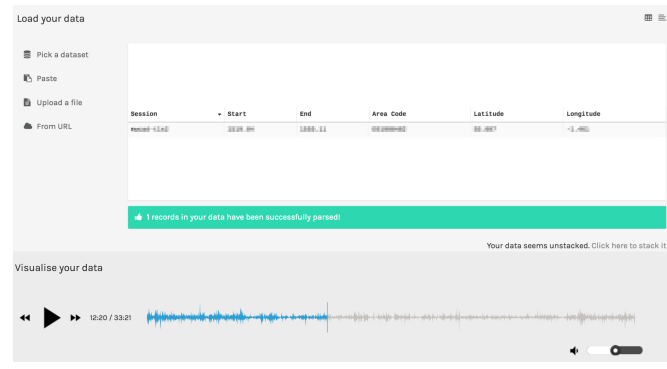

(b) Retrieved list of audio recordings

Fig. 5. Querying Citizen-Generated Data

these processes, which in turn raised issues around dependency and the misrepresentation of the communities.

Our open platform and the ideas of linking different datasets together through a place-based interface aims towards promoting 'effective use' [24] and supporting non-professionals and community groups in accessing and making sense of data in ways which are relevant to their matters of concern. Instead of presenting people with a set of information, the system starts with defining a place and then linking data to it. This enables communities to decide which data is relevant, and at what granularity is needed to surface the issues they are exploring. In the following sections, we will discuss the values we embedded in the platform derived from the design principles and assess their realisation through the co-design process. This includes reflection on the key parts of the system and its utility and current limitations as a tool for civic advocacy.

\subsection{Accessing Open Data}

Although national statistics and other official datasets were seen as a valuable resource for neighbourhood planning, it was very difficult for people to access. Even at the level of query-based searches, national statistics relating to local neighbourhoods are often categorised using postcodes, area names and ward boundaries; a system that is quite unlike the ways in which communities reference their own neighbourhoods. To overcome this, we developed a map-style interface that allowed people to identify neighbourhoods in ways with which they were familiar and a place-based query system (see Section 4.1) that enabled people to obtain national statistics for the neighbourhoods and issues they were considering.

Relating back to the first design principle with regards to making data relevant through place, we learned that an important aspect of contextualising data is making it relevant to the particularities of place understood both as a geographical place (i.e., locale) and as a social place, characterised by a community's interests and issues. The problem with big data in relation to abstract plans and procedures is that it always underspecifies the particularities of place. Work or procedures have to be abstractions relevant to the particular circumstances of their uses [43, 44]. What we discovered is that data is no different. Particularly big data, government data etc., is no different - its abstract materiality means that its relevance to place and to local issues is not always apparent, but it is something that has to be constructed, worked and made visible in order to provide value in these contexts. Only then can people start constructing knowledge from these abstract datasets, which will then open up spaces for enquires. We experienced this when we integrated place-based queries to the system and people started exploring available datasets situated in their neighbourhoods. Immediately, new questions were raised, as well as requests for additional datasets to be linked to 
the system for exploration. We tried to address this with integrated "request forms" through which people could request new datasets that were not currently linked through Data:In Place. While this significantly increases the accessibility to new open datasets on the platform, there is a required technical input from the research team and thus limits the extent to which the platform can be totally community sustained. Such issues are challenging but not insurmountable. One way forward here is to collaborate with official data providers (e.g., national and local governmental structure) to automatically link and publish their data through Data:In Place. Alternatively, we could make the 'dataset linking' more modular, promoting the open-source community to contribute to the project and start linking available open datasets to Data:In Place's place-based query system. By following a tutorial, people could commit additional code snippets to extend the project hosted on open code repository. This is even closer to the ideas of RAWGraphs' [35] "custom charts", which enable people to add their own chart templates for data visualising.

\subsection{Diversifying Participation}

The second design principle was to enable communities to challenge open data through their own experiences, which was realised in the tool by linking people's opinions on a place with official statistics. This give a more complete picture of the neighbourhood - providing context to open data or a way to challenge official statistics, but also surfacing the real needs and aspirations of the community. The importance of these was pointed out by one of the local charity workers CW2:

"I think there needs to be more of those conversations that sort of more they: "this is happening, this is how it's in the reality" in the just of things. And I like that, but I'm just thinking how we can make more of those conversations happen?"

Furthermore, open data can be used to contextualize community data, and representing both in the same platforms opens up the possibility for communities to speak back to government. There is often a presumption around both big data and open data, that its use-value for communities is both self-evident and veridical. This presumption is given credence by virtue of the idea that the data is somehow 'raw'. In contrast, Gitelman [22] argues that term ' raw data' is self-contradictory, since data is never raw, rather she argues that data begins its life as an act of imagination in response to a need or a question. It is created in order to meet a need, and thus it is always framed with respect to a human purpose. The analogy she uses is that of creating a photograph, a human decision is always made as to where the camera is pointed and at what angle. Data, like a photograph, indeed like any representation, has to be created, and that means it has to be created by people in response to their purposes. The fact that local community sees themselves so differently to how the data collected by outsiders portrays them, affirms that there is no such thing as 'raw data'. One limitation of our tool is that citizen data was generated by working with the system in co-located workshop settings. However, open data platforms like ours should promote wider participation and inclusion of ideas and voices. There is potential here for enabling a much broader participation through the online nature of the platform, enabling those not present in workshops to participate.

The mapping tool could also provide charities a way to understanding the work that other organisations do, by sharing some of their organisational data. Local charity worker CW6 talking about his experiences of finding out what work others do in the community:

"So, it seems that when we go into meetings, or when we meet with different organisations, people are doing very similar things or things that can help each other out quite a lot of the time and lot of the time a problem comes up as "uh I did not realise you are doing that", or "maybe we could help out along the same thing". So, as kind of providers of services it would be useful for us to know who is doing what, as well as the individuals who would be using those services as well." 
This kind of inter-visibility is important because in the past it has led to friction and competition between the groups. Not only would it remove the competitive element, it could lead to collaboration:

"[...] and if somebody feels threatened that you are kind of stepping on their toes then they can get maybe a little bit defensive about what they are doing. But if they would to understand fully what you were actually doing by using some kind of tool to gain that information and that can help put them at ease and then maybe help them feel a little bit more welcomed working alongside you as well." (CW6)

Working alongside each other they could also use the tool to collaboratively make sense of this data, to make a stronger case for additional funding and ultimately providing better services to the whole community. Similar findings were obtained in a study by Erete et al. [18] on the use of open data by Non-Profit Organisations (NPOs), where they emphasised that 'effective technologies' should help NPOs to access, interpret and collaboratively make sense of data related to their goals and objectives. Their work described the collaboration between NPOs and external data experts, however using Data:In Place and making the data truly open and accessible, NPOs could be more active in defining the issues they want to explore and collaborating with other NPOs to achieve common goals. This bring us to the value of these different sense makings and whether making data accessible and linked together with place will help people make sense of it and use it.

\subsection{Civic Advocacy and Action}

The third design principle we embedded in the platform was to integrate local knowledge and data to enrich collaboration and promote civic action. In designing Data:In Place aimed to help citizens in their endeavour to effectively use data for gathering evidence to contest the decisions in their community. Coming back to Gurstein's seven layer model [24] for 'effective use', we can see that Data:In Place does well against the first five, however there are more things that need to happen for effective use in civic advocacy. Our somewhat naïve assumptions that we could co-create a tool that would have a direct route to civic action was quickly proven to be premature. Technology can only go so far to make data accessible, help people interpret, make sense and visualise it, however it takes social capital to transform this data into activities for local benefit [24]. These people can be individual citizens or community organisations who are willing to own the problems, work on them and organise others to help advocate for change. Through our co-designing process, and by seeing that there are others who are passionate about tackling the same issues and improving their communities, these community organisers started to emerge and step up. Work by Voorberg et al. [50] reports that one of the influencing factors of citizen involvement in policy-making and co-creating of public services is poor communication channels, but also the attitudes of people in power not wanting to include citizens they cannot control and rely on. However, working closely with citizens and people in councils, we learned that decision-makers were interested in what the citizens were telling them, they just lacked the suitable means of communication to facilitate dialog. Perhaps it is more about collaboration and working together with the decision-makers rather than against them, and using a system as a medium to get expertise, add new meaning and different types of data to get everyone's views to be represented.

\subsection{Future Developments}

In our workshops we had groups working together to collectively understand the situation by looking at different sources of data and coming up with shared understandings through a process of collaborative sensemaking [19]. Data:In Place is effective in enabling better access to data as a resource for this collaborative process of forming shared understandings. However, the act of collaborative sensemaking itself, and the cognitive and social dimensions of it are not themselves 
documented. Related work by Otjacques et al. [37] has started looked at documenting open data exploration processes (i.e., viewpoints) for future interrogation and use. They built an additional layer on top of visualisation software which enabled viewpoints and scenarios to be stored, shared and reloaded at the exact state of visualisations when valuable knowledge was discovered. This functionality is future work for Data:In Place, but in addition to recording viewpoints, we envision a collaborative narrative-based interaction or 'data stories' which allows constant addition, documentation and interrogation of data. This also means that the new sense makings of the data is not owned by the institutions that published the datasets, it is more objective and based on a strong consensus of the community [48]. One example of this type of approach to data collection is Open Street $\mathrm{Map}^{35}$. It is a volunteered geographic information system [26, 45] where people (professionals and non-professionals) volunteer to map the world. In addition to volunteered geographic information by the people, the map also consists of repurposed data published by governmental institutions. Although the data originates from different sources, the new meaning and purpose of it is being generated as a result of collaborative efforts. The tool could also be extended to include help and expertise from outside to understand and explore issues using data science. This means adding a new layer of communication between citizens and experts.

\section{CONCLUSIONS}

Through the process of investigating people's relationship with data and how it might help them collaboratively make 'effective use' of it to have a stronger voice over what happens to their community, we discovered a set of roles that data plays in these processes. With Data:In Place, we illustrated that open data - when accessed correctly, presented fairly, tied up to a place and contextualised - can be a great tool for helping people explore issues and understand their communities. Our aim was to democratise data science in the hopes that the communities - who are the subject of this data - can become more than just the ones with the issues, but also active contributors of knowledge for tackling them. The platform we present was co-designed in the context of (1) neighbourhood plan, gathering evidence to back up their claims and (2) local charities, understanding the communities they operate in and for, and the impact they are having. We believe there is scope for our platform to support similar collaboration and sensemaking in other contexts where decision-makers and citizen data-subjects are otherwise siloed. Contexts where inclusion of, and collaboration between citizens and decision-makers in processes of making sense of and interpreting data, could be the key to tackling the problems of society.

\section{A AVAILABILITY}

Data:In Place is available at http://data-in.place.

\section{ACKNOWLEDGMENTS}

We wish to thank local charity staff and members of the community for their participation and support in carrying out this research. Big thanks to RAWGraphs' team for open-sourcing their awesome software. This research was funded through the EPSRC Centre for Doctoral Training in Digital Civics (EP/L016176/1). Data supporting this publication is not openly available due to ethical considerations, but may be possible under appropriate agreement. Additional metadata record at http://dx.doi.org/10.17634/154300-92. Please contact Newcastle Research Data Service at rdm@ncl.ac.uk for further information or access requests.

\footnotetext{
${ }^{35}$ http://openstreetmap.org
} 


\section{REFERENCES}

[1] Mariam Asad, Christopher A. Le Dantec, Becky Nielsen, and Kate Diedrick. 2017. Creating a Sociotechnical API: Designing City-Scale Community Engagement. In Proceedings of the 2017 CHI Conference on Human Factors in Computing Systems (CHI '17). ACM, New York, NY, USA, 2295-2306. https://doi.org/10.1145/3025453.3025963

[2] Stefan Baack. 2015. Datafication and empowerment: How the open data movement re-articulates notions of democracy, participation, and journalism. Big Data \& Society 2, 2 (2015), 1-11. https://doi.org/10.1177/2053951715594634

[3] M. Balestrini, T. Diez, P. Marshall, A. Gluhak, and Y. Rogers. 2015. IoT Community Technologies: Leaving Users to Their Own Devices or Orchestration of Engagement? EAI Endorsed Transactions on Internet of Things 1, 1 (10 2015). https://doi.org/10.4108/eai.26-10-2015.150601

[4] Mara Balestrini, Yvonne Rogers, Carolyn Hassan, Javi Creus, Martha King, and Paul Marshall. 2017. A City in Common: A Framework to Orchestrate Large-scale Citizen Engagement Around Urban Issues. In Proceedings of the 2017 CHI Conference on Human Factors in Computing Systems (CHI '17). ACM, New York, NY, USA, 2282-2294. https://doi.org/10.1145/3025453.3025915

[5] Mara Balestrini, Yvonne Rogers, and Paul Marshall. 2015. Civically Engaged HCI: Tensions Between Novelty and Social Impact. In Proceedings of the 2015 British HCI Conference (British HCI '15). ACM, New York, NY, USA, 35-36. https://doi.org/10.1145/2783446.2783590

[6] Kirsten Boehner and Carl DiSalvo. 2016. Data, Design and Civics: An Exploratory Study of Civic Tech. In Proceedings of the 2016 CHI Conference on Human Factors in Computing Systems (CHI '16). ACM, New York, NY, USA, 2970-2981. https://doi.org/10.1145/2858036.2858326

[7] Cameron William Bruce. 1963. Informal Sociology: A Casual Introduction to Sociological Thinking. Random House, New York. 1-14 pages.

[8] John M. Carroll and Mary Beth Rosson. 2013. Wild at Home: The Neighborhood As a Living Laboratory for HCI. ACM Trans. Comput.-Hum. Interact. 20, 3, Article 16 (July 2013), 28 pages. https://doi.org/10.1145/2491500.2491504

[9] Joohee Choi and Yla Tausczik. 2017. Characteristics of Collaboration in the Emerging Practice of Open Data Analysis. In Proceedings of the 2017 ACM Conference on Computer Supported Cooperative Work and Social Computing (CSCW'17). ACM, New York, NY, USA, 835-846. https://doi.org/10.1145/2998181.2998265

[10] Sophie Chou, William Li, and Ramesh Sridharan. 2014. Democratizing Data Science Effecting positive social change with data science. In KDD at Bloomberg. http://people.csail.mit.edu/wli/papers/ Chou-Li-Sridharan-DemocratizingDataScience.pdf

[11] H. Chourabi, T. Nam, S. Walker, J. R. Gil-Garcia, S. Mellouli, K. Nahon, T. A. Pardo, and H. J. Scholl. 2012. Understanding Smart Cities: An Integrative Framework. In 2012 45th Hawaii International Conference on System Sciences. IEEE, Hawaii, HA, USA, 2289-2297. https://doi.org/10.1109/HICSS.2012.615

[12] Adrian K. Clear, Sam Mitchell Finnigan, Patrick Olivier, and Rob Comber. 2017. "I’D Want to Burn the Data or at Least Nobble the Numbers": Towards Data-mediated Building Management for Comfort and Energy Use. In Proceedings of the 2017 ACM Conference on Computer Supported Cooperative Work and Social Computing (CSCW'17). ACM, New York, NY, USA, 2448-2461. https://doi.org/10.1145/2998181.2998188

[13] Claire Colomb. 2017. Participation and conflict in the formation of neighbourhood areas and forums in super-diverse cities. In Localism and Neighbourhood Planning: Power to the People?, S Brownell and Q Bradley (Eds.). Policy Press, Bristol, 127-144.

[14] Andy Crabtree, Tom Lodge, James Colley, Chris Greenhalgh, Richard Mortier, and Chris Greenghalgh. 2017. Accountable Internet of Things? Outline of the IoT Databox Model. (2017). http://eprints.nottingham.ac.uk/42233/1/IoT_SoS.pdf

[15] Tim Davies and Mark Frank. 2013. 'There's No Such Thing As Raw Data': Exploring the Socio-technical Life of a Government Dataset. In Proceedings of the 5th Annual ACM Web Science Conference (WebSci '13). ACM, New York, NY, USA, 75-78. https://doi.org/10.1145/2464464.2464472

[16] Department for Local Communities and Government. 2017. Neighbourhood Planning Act 2017. http://www.legislation. gov.uk/ukpga/2017/20/contents/enacted

[17] Carl DiSalvo, Marti Louw, Julina Coupland, and MaryAnn Steiner. 2009. Local Issues, Local Uses: Tools for Robotics and Sensing in Community Contexts. In Proceedings of the Seventh ACM Conference on Creativity and Cognition (C\&C '09). ACM, New York, NY, USA, 245-254. https://doi.org/10.1145/1640233.1640271

[18] Sheena Erete, Emily Ryou, Geoff Smith, Khristina Marie Fassett, and Sarah Duda. 2016. Storytelling with Data: Examining the Use of Data by Non-Profit Organizations. In Proceedings of the 19th ACM Conference on ComputerSupported Cooperative Work \& Social Computing (CSCW '16). ACM, New York, NY, USA, 1273-1283. https://doi.org/10. $1145 / 2818048.2820068$

[19] George W. Furnas and Daniel M. Russell. 2005. Making Sense of Sensemaking. In CHI '05 Extended Abstracts on Human Factors in Computing Systems (CHI EA '05). ACM, New York, NY, USA, 2115-2116. https://doi.org/10.1145/1056808 1057113 
[20] Sarah Gallacher, Christian Jetter, Vaiva Kalnikaite, Julie Mccann, David Prendergast, and Jon Bird. 2014. Investigating the Challenges of Crowd Sensing: Lessons from Zurich. In Workshop "Structures of Knowledge Co-creation Between Organisations and the Public" (A Workshop at ACM CSCW 2014). https://www.researchgate.net/publication/262376287 Investigating_the_Challenges_of_Crowd_Sensing_Lessons_from_Zurich

[21] Nick Gallent and Steve Robinson. 2012. Neighbourhood planning: communities, networks and governance. Policy Press, Bristol.

[22] Lisa Gitelman. 2013. "Raw Data" Is an Oxymoron. MIT Press. 1-14 pages.

[23] Connie Golsteijn, Sarah Gallacher, Licia Capra, and Yvonne Rogers. 2016. Sens-Us: Designing Innovative Civic Technology for the Public Good. In Proceedings of the 2016 ACM Conference on Designing Interactive Systems (DIS '16) ACM, New York, NY, USA, 39-49. https://doi.org/10.1145/2901790.2901877

[24] B Michael Gurstein. 2011. Open data: Empowering the empowered or effective data use for everyone? First Monday 16, 2 (2011). http://firstmonday.org/article/view/3316/2764

[25] David Hakken. 2003. A Social Informatics Approach to Knowledge in Cyberspace. In The Knowledge Landscapes of Cyberspace. Chapter 6, 145-177.

[26] Muki Haklay. 2013. Citizen Science and Volunteered Geographic Information - overview and typology of participation. In Crowdsourcing Geographic Knowledge: Volunteered Geographic Information (VGI) in Theory and Practice, Daniel Sui, Sarah Elwood, and Michael Goodchild (Eds.). Vol. 9789400745. Springer, Berlin, Chapter 7, 105-122. https: //doi.org/10.1007/978-94-007-4587-2_7

[27] Derek L. Hansen, Jes A. Koepfler, Paul T. Jaeger, John C. Bertot, and Tracy Viselli. 2014. Civic Action Brokering Platforms: Facilitating Local Engagement with ACTion Alexandria. In Proceedings of the 17th ACM Conference on Computer Supported Cooperative Work \&\#38; Social Computing (CSCW'14). ACM, New York, NY, USA, 1308-1322. https://doi.org/10.1145/2531602.2531714

[28] Marijn Janssen, Yannis Charalabidis, and Anneke Zuiderwijk. 2012. Benefits, Adoption Barriers and Myths of Open Data and Open Government. Information Systems Management 29, 4 (2012), 258-268. https://doi.org/10.1080/10580530. 2012.716740

[29] Thorhildur Jetzek, Michel Avital, and Niels Bjorn-Andersen. 2014. Data-Driven Innovation through Open Government Data. Journal of theoretical and applied electronic commerce research 9 (05 2014), 100 - 120. https://scielo.conicyt.cl/ scielo.php?script=sci_arttext\&pid=S0718-18762014000200008\&nrm=iso

[30] Ian G. Johnson, Alistair MacDonald, Jo Briggs, Jennifer Manuel, Karen Salt, Emma Flynn, and John Vines. 2017. Community Conversational: Supporting and Capturing Deliberative Talk in Local Consultation Processes. In Proceedings of the 2017 CHI Conference on Human Factors in Computing Systems (CHI '17). ACM, New York, NY, USA, 2320-2333. https://doi.org/10.1145/3025453.3025559

[31] Maxat Kassen. 2013. A promising phenomenon of open data: A case study of the Chicago open data project. Government Information Quarterly 30, 4 (2013), 508 - 513. https://doi.org/10.1016/j.giq.2013.05.012

[32] Rob Kitchin, Tracey P. Lauriault, and Gavin McArdle. 2015. Knowing and governing cities through urban indicators, city benchmarking and real-time dashboards. Regional Studies, Regional Science 2, 1 (2015), 6-28. https://doi.org/10 1080/21681376.2014.983149

[33] Christopher A. Le Dantec, Mariam Asad, Aditi Misra, and Kari E. Watkins. 2015. Planning with Crowdsourced Data: Rhetoric and Representation in Transportation Planning. In Proceedings of the 18th ACM Conference on Computer Supported Cooperative Work \&\#38; Social Computing (CSCW '15). ACM, New York, NY, USA, 1717-1727. https: //doi.org/10.1145/2675133.2675212

[34] Siân E. Lindley, Anja Thieme, Alex S. Taylor, Vasilis Vlachokyriakos, Tim Regan, and David Sweeney. 2017. Surfacing Small Worlds through Data-In-Place. Computer Supported Cooperative Work 26, 1-2 (apr 2017), 135-163. https: //doi.org/10.1007/s10606-017-9263-3

[35] Michele Mauri, Tommaso Elli, Giorgio Caviglia, Giorgio Uboldi, and Matteo Azzi. 2017. RAWGraphs: A Visualisation Platform to Create Open Outputs. In Proceedings of the 12th Biannual Conference on Italian SIGCHI Chapter (CHItaly '17). ACM, New York, NY, USA, Article 28, 5 pages. https://doi.org/10.1145/3125571.3125585

[36] Patrick Olivier and Peter Wright. 2015. Digital Civics: Taking a Local Turn. interactions 22, 4 (June 2015), 61-63. https://doi.org/10.1145/2776885

[37] Benoît Otjacques, Mickaël Stefas, Maël Cornil, and Fernand Feltz. 2012. Open Data Visualization Keeping Traces of the Exploration Process. In Proceedings of the First International Workshop on Open Data (WOD '12). ACM, New York, NY, USA, 53-60. https://doi.org/10.1145/2422604.2422612

[38] Sylvain Parasie and Eric Dagiral. 2013. Data-driven journalism and the public good: "Computer-assisted-reporters" and "programmer-journalists" in Chicago. New Media \& Society 15, 6 (2013), 853-871. https://doi.org/10.1177/ 1461444812463345

[39] Aare Puussaar, Adrian K Clear, and Peter Wright. 2017. Enhancing Personal Informatics Through Social Sensemaking. In Proceedings of the 2017 CHI Conference on Human Factors in Computing Systems - CHI '17. ACM Press, New York, 
New York, USA, 6936-6942. https://doi.org/10.1145/3025453.3025804

[40] David G. Robinson, Yu Harlan, and Edward W. Felten. 2010. Enabling innovation for civic engagement. In Open government: Collaboration, transparency and participation in practice. Chapter 6, 85-92.

[41] Yvonne Rogers. 2011. Interaction Design Gone Wild: Striving for Wild Theory. Interactions 18, 4 (2011), 58-62. https://doi.org/10.1145/1978822.1978834

[42] John Stanton. 2014. The Big Society and Community Development: Neighbourhood Planning under the Localism Act. Environmental Law Review 16, 4 (2014), 262-276. https://doi.org/10.1350/enlr.2014.16.4.225

[43] Lucy Suchman. 2007. Human-Machine Reconfigurations (2 ed.). Vol. 2. Cambridge University Press.

[44] Alex S. Taylor, Siân Lindley, Tim Regan, David Sweeney, Vasillis Vlachokyriakos, Lillie Grainger, and Jessica Lingel. 2015. Data-in-Place: Thinking Through the Relations Between Data and Community. (2015), 2863-2872. https: //doi.org/10.1145/2702123.2702558

[45] Matthew Tenney and Renee Sieber. 2016. Data-Driven Participation: Algorithms, Cities, Citizens, and Corporate Control. Urban Planning 1, 2 (2016), 101-113. https://doi.org/10.17645/up.v1i2.645

[46] Anthony M Townsend. 2013. Smart Cities: Big Data, Civic Hackers, and the Quest for a New Utopia. W. W. Norton \& Company.

[47] José van Dijck. 2014. Datafication, dataism and dataveillance: Big data between scientific paradigm and ideology. Surveillance and Society 12, 2 (2014), 197-208.

[48] Janet Vertesi and Paul Dourish. 2011. The Value of Data: Considering the Context of Production in Data Economies. In Proceedings of the ACM 2011 Conference on Computer Supported Cooperative Work (CSCW'11). ACM, New York, NY, USA, 533-542. https://doi.org/10.1145/1958824.1958906

[49] Vasilis Vlachokyriakos, Rob Comber, Karim Ladha, Nick Taylor, Paul Dunphy, Patrick McCorry, and Patrick Olivier 2014. PosterVote: Expanding the Action Repertoire for Local Political Activism. In Proceedings of the 2014 Conference on Designing Interactive Systems (DIS '14). ACM, New York, NY, USA, 795-804. https://doi.org/10.1145/2598510.2598523

[50] W. H. Voorberg, V. J. J. M. Bekkers, and L. G. Tummers. 2015. A Systematic Review of Co-Creation and Co-Production: Embarking on the social innovation journey. Public Management Review 17, 9 (2015), 1333-1357. https://doi.org/10. 1080/14719037.2014.930505

[51] William Foote Whyte. 1991. Participatory action research. Sage Publications.

Received April 2018; revised July 2018; accepted September 2018 